Document downloaded from:

http://hdl.handle.net/10251/99456

This paper must be cited as:

Serrano Iribarnegaray, L.; Martinez-Roman, J. (2007). A Unified Approach to the Very Fast Torque Control Methods for DC and AC Machines. IEEE Transactions on Industrial Electronics. 54(4):2047-2056. doi:10.1109/TIE.2007.895148

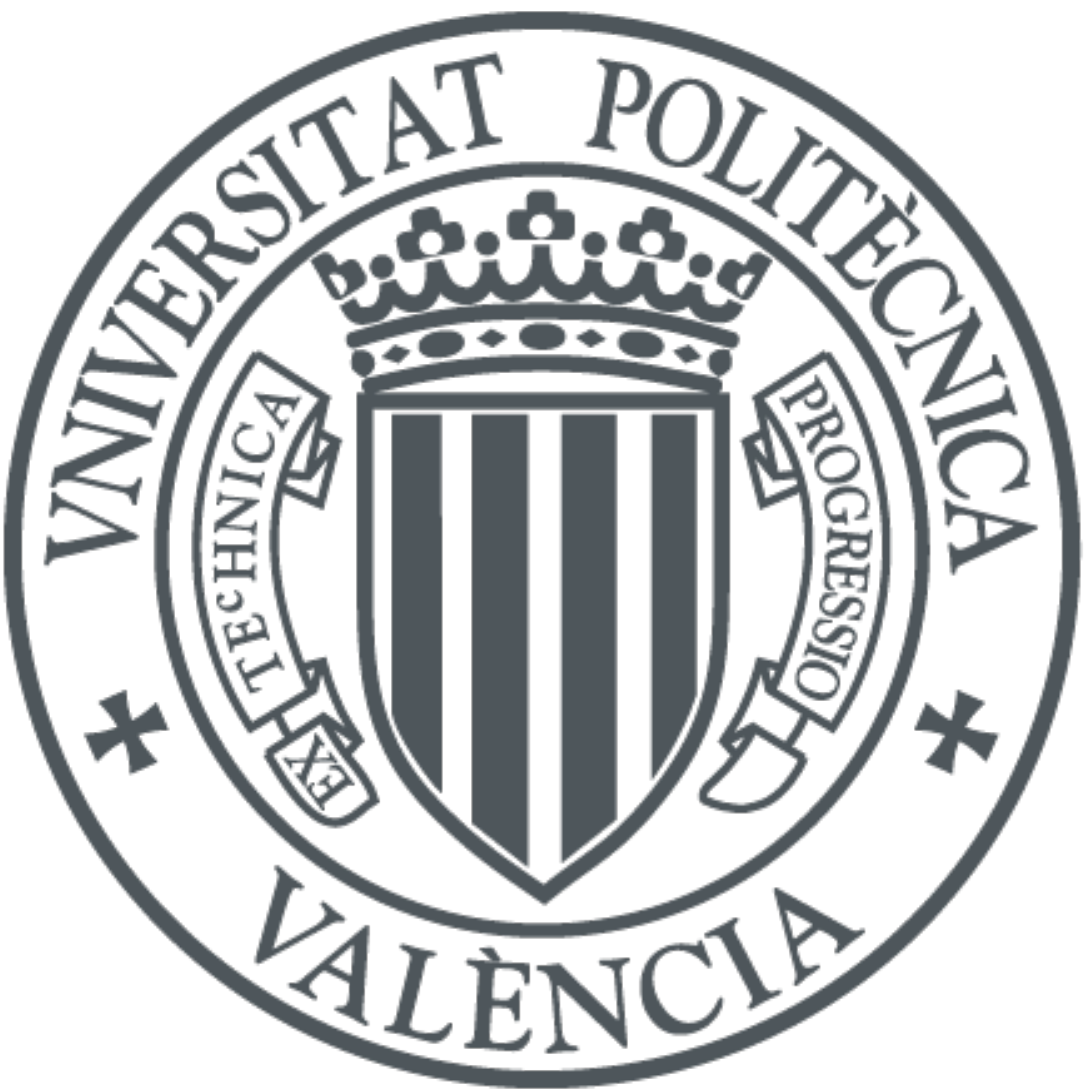

The final publication is available at

http://doi.org/10.1109/TIE.2007.895148

Copyright Institute of Electrical and Electronics Engineers

Additional Information 


\title{
A unified approach to the very fast torque con- trol methods for DC and AC machines.
}

\author{
Luis Serrano-Iribarnegaray, Javier Martínez-Román
}

\begin{abstract}
The general strategy to get a very fast torque control in a DC or AC machine is based on keeping the pulsational emfs of all of its phases as small as possible during transient states and achieving the torque changes by exclusively enhancing the rotational emfs. All the resources available have to be oriented in this direction. This very simple but profound physical idea, when applied to DC or AC machines, allows the different control methods for these machines developed to date and regarded as the best from a dynamic point of view to be deduced in a unified, systematic and straightforward way.
\end{abstract}

Index Terms - DC and AC Motor Drives, Direct Torque Control, Field-Oriented Control, Vector Control, Space phasors.

\section{INTRODUCTION}

ARIABLE speed drives have been used in industry for many decades. The first motors used to this end were DC motors with separate excitation. Initially, speed control below the base speed was achieved using a wasteful resistance in the armature circuit. However, after H. Ward Leonard's proposal [1], it gradually became accepted that the best solution was obtained by keeping the excitation constant and varying the armature voltage.

When, from the sixties onwards, variable speed drives with squirrel cage motors became more and more popular (favoured by the development of power electronics), the wellknown volts/hertz control was first applied. Thereafter, relying on the works of Hasse [2] and Blaschke [3], [4], the so called field-orientation control (FOC) became widespread, its physical analogy with the DC machine control was underlined and the method was claimed to provide the optimum dynamic response. However, a few years later, the direct self control (DSC) [5], [6] and the direct torque control (DTC) [7] methods were developed and it was stated that, besides their greater simplicity and robustness against motor parameter changes, they were also superior to FOC as to the dynamic behaviour (e.g., Section VI in [7]).

For doubly fed asynchronous machines (DFAM) various control strategies based mainly as well on FOC and DTC have been recommended (e, g. [8] - [10])

For permanent magnet synchronous motors (PMSM) with exterior permanent magnets (PM), keeping the stator current

L. Serrano-Iribarnegaray is with the Electrical Engineering Department Universidad Politécnica de Valencia, Spain (phone: 34-96-387-75-97; fax: 3496-387-75-99; e-mail: 1serrano@die.upv.es).

J. Martínez-Román is with the Electrical Engineering Department - Universidad Politécnica de Valencia, Spain (e-mail: jmroman@die.upv.es). sheet aligned with the rotor magnet (that is, orthogonalizing stator and rotor fields) has long been proposed as the optimal mode of operation [11] as it provides maximum torque per stator ampere. The maximum torque per ampere strategy has also been applied [12] to PMSM with interior PM, although in this case the stator current sheet and rotor magnet are, of course, no longer aligned. Other authors, on the contrary, prefer to keep the above-mentioned alignment even for motors with interior PM. On the other hand, the DTC has also been presented as an alternative control method with clear advantages and valid for both kinds of PMSM [13].

As for the synchronous motors with wound rotor, apart from the current-fed self-controlled machine mode of operation (quite similar in its behaviour to the DC machine), there have also been different control proposals in the technical literature [14] - [17].

The situation outlined is quite unsatisfactory. Indeed, it is very often stated that there is, in reality, only one DTC method with two slightly different versions (those cited in [6] and [7]), which is, at least, clearly questionable. Likewise, there is a general consensus that there are two main alternatives for high performance torque control of all AC machines, FOC and DTC, which are regarded as two clearly different and unrelated techniques (see, e. g., page 408 of [18], where, in contrast to FOC, DTC is considered an "advanced scalar control technique"). But again, this statement on only two main methods is rather misleading, for the general term "FOC" does not define a unique control strategy, as there are rotor (RFOC), stator (SFOC) and air gap flux oriented control methods with no clear rules or laws as to the suitable option in each case (for instance, which "field oriented" coordinates to choose to get the fastest dynamic response in the synchronous motor or in the DFAM? and why?). Moreover, especially in induction motors, several coordinates transformations other than the three classical "field oriented" transformations can also be selected to achieve decoupling and linearization of the machine equations, [19].

In view of these facts, this paper first tackles the following question: is it possible to establish a general approach which allows deducing and developing control methods for DC and $\mathrm{AC}$ machines in a unified and systematic way so as to always get a very fast dynamic torque response?

This question is discussed and answered affirmatively in Section II, stating what is called the general approach or general principle for a very fast dynamic torque control (GAFTOC) and which relies on a very simple but profound 
physical idea: one must try to achieve that the energy conversion process during transient states takes place under the exclusive presence of rotational emfs, just as happens in steady state.

This fundamental idea is applied in a systematic way to DC machines (Section III) and all industrial AC machines: squirrel cage motors (Section IV), doubly fed asynchronous machines (Section V) and synchronous machines with PM or with wound rotor (Section IV). This results in getting all of the control methods for these machines developed to date and regarded in the technical literature as being the best from a dynamic point of view.

In Section III, the traditional viewpoint to study the DC motor control is abandoned in favour of the new GAFTOC perspective. This motor is suitable to begin with, as the problem associated with it comes down to analyzing the emfs in just two single windings.

Section IV is the longest one because it shows in detail and for the first time how to apply GAFTOC to an AC machine, and also because of the great industrial importance of the induction motor. In this section it also becomes clear that, from a conceptual viewpoint, the FOC and DTC methods are not so different as is usually stated, but that the truth is rather just the opposite: they can be regarded as the two logical options when trying to fulfil the GAFTOC requirements.

Applying GAFTOC to the DFAM in Section V leads to a unique solution which calls for a control strategy very recently presented in [9], [10], and discussed in detail with various proposals for improvements in [20].

Section VI applies GAFTOC to synchronous motors with wound rotor or with PM. As to the latter type, it is shown that there are also, as in the induction motor, two logical options for getting a very fast dynamic response, one of which being the well known method of orthogonalizing stator and rotor fields. In synchronous motors with wound rotors fed through a cycloconverter, the GAFTOC points to a new control structure with certain differences with respect to one of the best published in the technical literature, which is also discussed in the paper.

Finally, Section VII provides a new insight into the comparison between FOC, DTC and DSC, emphasising the novel similarities and differences that arise when they are examined from the GAFTOC viewpoint.

\section{GENERAL APPROACH FOR A VERY FAST TORQUE CONTROL} (GAFTOC)

The phases of a rotating electrical machine are built, in the general case, by the interconnection of coils, and can be either short-circuited or connected to an electric source.

With the only purpose of introducing in a very brief and intuitive way the fundamental idea underlying fast torque control, let us consider the simplest case of a single short-circuited coil. If the coil is placed within a rotating magnetic field of constant amplitude and arbitrary speed, a so called rotational emf is induced in the coil which drives a current trough it and creates a torque. However, if the field's spatial orientation remains constant and only its amplitude changes over time in an arbitrary manner, and if the field and coil axes are aligned, a purely pulsational emf is induced in the coil, which also drives a current, but, no matter how big the current may be, there is no torque now. Therefore, it is clear that in order to produce motion this pulsational emf is useless and, moreover, one must regard it as a waste of resources and time (the time required for producing the current associated with the pulsational emf). In a nutshell, the motional emf is concerned with electromechanical energy conversion, while the pulsational emf provides a means of electrical energy transfer between magnetically coupled circuits.

As indicated in the coil example, the speed (rotational emf) or the oscillation frequency (pulsational emf) of the field may be constant or vary in an arbitrary manner and the above conclusions remain valid in both cases. Notice that, although virtually ignoring this principle, electrical engineers, in fact, have resorted to it for efficient utilization of the machine, but only in steady state. Indeed, it is easy to check that in steady state of DC and symmetrical AC machines, the electromechanical energy conversion process takes place under the exclusive presence of only rotational emfs, and these emfs are the only ones enhanced. There is no machine winding at all in which a pulsational emf appears in steady state: the emfs induced in the windings are either rotational (as in the polyphase windings ${ }^{1}$ ) or null (as in the field winding of DC and synchronous machines).

There are no reasons to restrict this mode of operation to steady states in converter-fed electrical machines. In other words, regarding the nature of the emfs induced in the windings, the energy conversion process during transient state must evolve as in steady state, which will result in a fast dynamic response and a efficient utilization of the machine (and of the power conditioning unit).

Therefore, the strategy to get very fast machine torque control is based on keeping the pulsational emfs of all of its phases as small as possible during transients and achieving torque changes by exclusively enhancing the rotational emfs. All the resources available have to be oriented in this direction. This statement constitutes the general approach or general strategy for a very fast dynamic torque control (GAFTOC) in DC or symmetrical AC machines ${ }^{2}$.

\section{VERY FAST TORQUE CONTROL OF DIRECT CURRENT MACHINES}

Let us briefly review the classical control method below the base speed of a DC motor with separate excitation.

The armature is connected to the output of a controlled rec-

\footnotetext{
${ }^{1}$ Transient phenomena in converter fed AC machines and their control are worldwide analyzed by considering only the fundamental space waves (which can be characterized by space phasors). This hypothesis is also maintained in this paper. Thus, the pulsational e.m.f. of a stator or rotor polyphase winding here referred to is simply the one due to the magnitude variation ("pulsation") of its flux linkage space phasor, $\Psi$, whereas the rotational e.m.f. is the one produced by the rotation of $\Psi$ in a reference frame fixed to the winding

${ }^{2}$ In this paper it is always assumed that AC machines have two or more symmetrical phases. In AC single phase machines it makes no sense at all to demand a transient evolution without pulsational emfs, as not even in steady state can they be eliminated.
} 
tifier or chopper and the field excitation winding to a constant voltage source in order to get a constant field current, $\mathrm{i}_{\mathrm{f}}$ (See Fig. 1 where, in order to underline the analogies with subsequent $\mathrm{AC}$ machines control structures, $\mathrm{i}_{\mathrm{f}}$ is obtained by means of a current controller ). Moreover, the brushes are placed so that the armature and excitation m.m.f. waves are orthogonal to each other. In this way, the pole flux, $\Phi_{\mathrm{p}}$, is equal to the flux between the brushes, $\Phi_{b}$, and remains practically constant, regardless of the armature current, $i_{a}$. To increase the torque, the armature voltage is duly increased, whereupon $i_{a}$ increases and so does the torque $\left(T=K \cdot \Phi_{b} \cdot i_{a}\right)$ as well. Notice that there is no pulsational emf in the field winding during this transient process.

It is important first of all to be aware that if a controlled converter without restrictions as to voltage and current were available, then the brushes may be placed, in principle, at any position. For instance, assume the brushes are shifted in the usual direction to improve commutation. In this case, increasing the current $i_{a}$ would mean reducing $\Phi_{\mathrm{p}}$ as well as $\Phi_{\mathrm{b}}$, and, therefore, more $i_{a}$ would be needed to provide the same torque. However, one could get the required torque, and as quickly as before, simply by applying more armature voltage, which would result in the current increasing faster and reaching a larger final value. (Of course, not only the converter, but also the commutator and the armature winding must be able to withstand this greater final value). These facts clearly show that if there are no restrictions as to the resources available, there is no point in questioning which method is the best, simply because practically any method (in the example under study: brushes at any position) could provide the same dynamic torque performance.

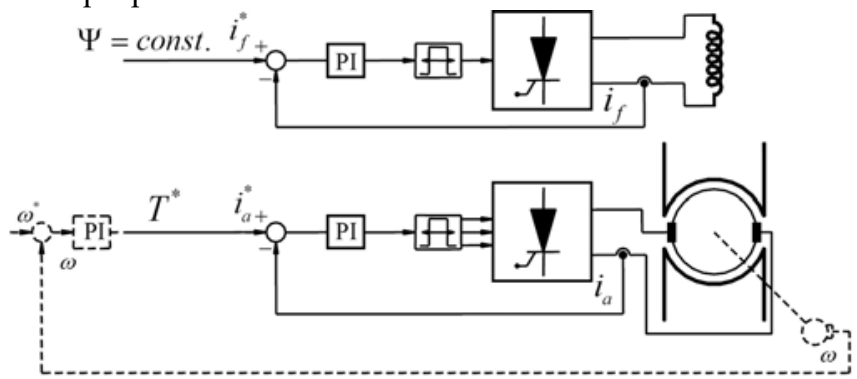

Fig.1. DC Machine control. In the subsequent schemes the speed control loop will be omitted to focus attention on torque and flux control. Field weakening operation is not considered in this paper.

From the above considerations it becomes clear that with a given converter (specified restrictions), shifting the brushes from their neutral position results in a method with a worse dynamic response. From the traditional viewpoint the reason is said to be that flux and current are no longer decoupled, which is true. However, from the new GAFTOC perspective it can also be stated that with the brushes shifted, changing the armature current results in a pulsational emf in the excitation winding, which, according to what has been explained, must produce degradation of the dynamic response and underutilisation of motor and rectifier.

Now, assuming a given converter and after having placed the brushes at their correct position the question arises whether it is possible to still improve the dynamic torque response or whether, on the contrary, the limit has already been attained. Answering this question requires investigating whether there are still dynamic pulsational emfs remaining in the system and whether they can be eliminated or, at least, reduced. And it is easy to see that during the transients the quadrature axis pulsating field due to the armature current variations self-induces a pulsational emf in the armature winding. The only margin left to try to improve the dynamic response, if at all possible, must lie in this emf. Using a second controlled rectifier in the excitation winding in order to counteract (by means of suitable $\mathrm{i}_{\mathrm{f}}$ variations) the instantaneous armature field variations is a proposal doomed to failure, simply because the direct axis magnetic field of the excitation (Fig. 1) can never eliminate a quadrature axis magnetic field. Of course, a second proposal of eliminating the $i_{a}$ variations during torque variations makes no sense at all. However, it is known that although the armature winding rotates, it produces (thanks to the brushescommutator set) a magnetic field with a fixed spatial orientation and whose amplitude varies in step with $i_{a}$. Based on this fact, there is a third (and this time successful) proposal: to counteract the armature field by a fixed winding fed with $i_{a}$ and placed so as to produce an opposite quadrature axis field. This is the compensating winding which, as is well known, DC machines meant for very fast response are provided with. Of course, since the machine quadrature axis field has practically been eliminated, there is almost no pulsational emf induced in the compensating winding either.

To sum up, finding the best dynamic solution for DC machine control coincides with eliminating the pulsational emfs in all of its windings (armature, excitation and compensating windings) during transients.

\section{VERY FAST TORQUE CONTROL OF SQUIRREL CAGE INDUCTION MOTORS}

In symmetrical stator or rotor polyphase windings, and with the usual assumption that only the fundamental machine space waves are taken into account, determining the flux linkage of any phase by means of space phasors [21], [31] is quite simple: it is proportional to the projection on the phase axis of the corresponding flux linkage space phasor.

In induction machines, the stator or rotor flux linkage space phasor in the stator or rotor reference frame, respectively, is given in the general case by

$\overrightarrow{\Psi_{x}}=\Psi_{x}(t) e^{j \alpha_{x}(t)}$

Fig. 2 shows the derivative of the $\Psi_{\mathbf{x}}$ phasor in the $\mathrm{x}$ reference frame, which is equal to the corresponding emf space phasor ( $\mathrm{x}=$ stator or rotor $)$, that is:

$$
\begin{gathered}
\overrightarrow{e_{x}}=-\frac{d}{d t} \overrightarrow{\Psi_{x}}=-\frac{d}{d t}\left[\Psi_{x}(t) e^{j \alpha(t)}\right]= \\
=-\frac{d\left[\Psi_{X}(t)\right]}{d t} e^{j \alpha(t)}-j \frac{d[\alpha(t)]}{d t} \overrightarrow{\Psi_{x}}=\overrightarrow{e_{x, \text { puls }}}+\overrightarrow{e_{x, \text { rot. }}}
\end{gathered}
$$

The total emf induced in a phase is given by the projection of the $\mathbf{e}_{\mathbf{x}}$ phasor on the phase axis. This phasor, in turn, can be decomposed into the pulsational and the rotational emf space phasors. The former only exists when there are variations in 
the $\Psi_{\mathbf{x}}$ magnitude and is aligned with it, whereas the latter only exists when there are variations in the $\Psi_{\mathbf{x}}$ orientation, that is, if $\Psi_{\mathbf{x}}$ rotates, and is orthogonal to it.

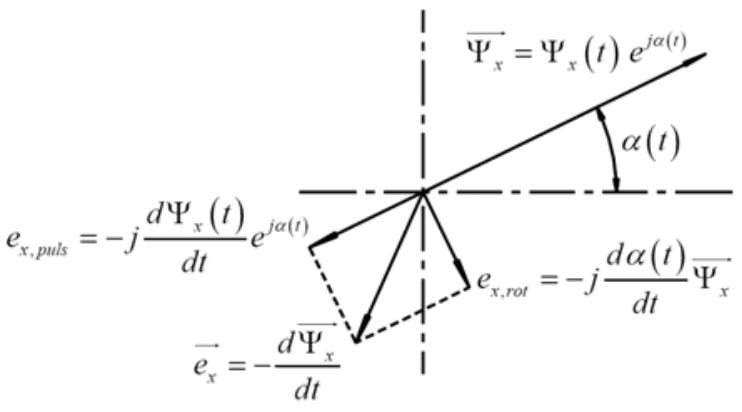

Fig.2. Flux linkage space phasor, $\Psi_{\mathrm{x}}$, and space phasor of induced emf (total, rotational and pulsational)

Therefore, according to (2), keeping the pulsational emfs null in all of the stator or rotor phases during any transient is achieved simply by keeping the magnitude of $\Psi_{\text {str }}$ or $\Psi_{\text {rot }}$, respectively, constant. In other words, to get a fast dynamic torque response, only the rotational speed of $\Psi$ has to be changed during the transient. The faster this speed changes, the greater the rotational emfs induced in the winding and, therefore, according to Section II, the quicker the torque changes.

Let us now consider an induction motor fed through an electronic converter. Since stator and rotor currents are interrelated, it is possible, by means of a suitable control, to force the converter to deliver a set of stator currents so that either $\Psi_{\text {str }}$

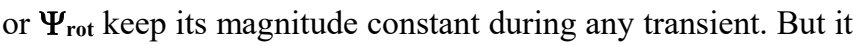
is impossible to simultaneously and independently control the stator and rotor currents, since this would require feeding the stator and the squirrel cage rotor with two independent electric sources. Therefore, in this machine the ideal aim of eliminating the pulsational emfs in all of its windings can never be accomplished.

In view of these facts, one has to choose to keep either the $\Psi_{\text {rot }}$ or the $\Psi_{\text {str }}$ magnitude constant.

Let us analyze the first option. In the rotor winding of the asynchronous motor, since there are no external voltages applied, the following equation always holds

$\overrightarrow{e_{\text {rot }}}=R_{\text {rot }} \overrightarrow{i_{\text {rot }}}$

In other words, the emf and current space phasors of the rotor are always aligned. Moreover, according to Fig. 2 and (2), the fact that the rotor emf is purely rotational implies that the space phasors $\Psi_{\text {rot }}$ and erot are perpendicular to each other, which in turn means that, according to (3), the $\mathbf{i}_{\text {rot }}$ and $\Psi_{\text {rot }}$ phasors are perpendicular too. On the other hand, since stator and rotor currents are interrelated, it is very easy to prove (see appendix) that keeping $\mathbf{i}_{\text {rot }}$ and $\Psi_{\text {rot }}$ orthogonal to each other is equivalent to stating that the affix of the is phasor moves along a straight line perpendicular to $\Psi_{\text {rot }}$ during any transient. In other words, fast torque changes (associated in this first control option to null pulsational emfs in the rotor windings) must be achieved changing only the $q$ component of the space phasor $\mathbf{i}_{\text {s }}$ in a reference frame tied to $\Psi_{\text {rot }}$ which leads immediately to the block control scheme of Fig. 3 This constitutes the
RFOC method expressed in the formulation by Blaschke [3], [4] also called direct RFOC. (Coordinates transformations, flux angle estimation etc. in this and in subsequent schemes are particular technological tasks very well known in the technical literature and whose analysis does not belong to a general paper).

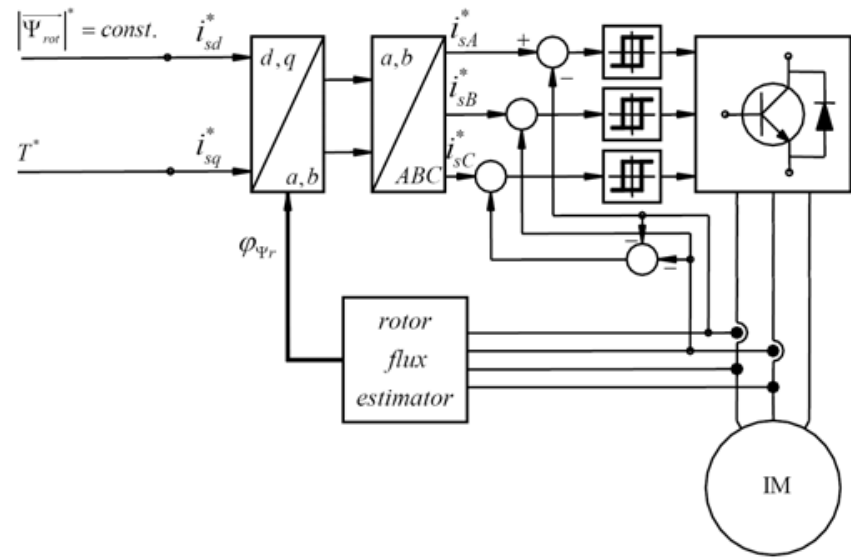

Fig.3. Direct Rotor Field Oriented Control of an induction machine

It is now appropriate to remember that the two following equations always hold in the induction machine $\left(\mathrm{C}_{1}\right.$ and $\mathrm{C}_{2}$ are two machine constants)

$T(t)=C_{1} \Psi_{\text {rot }}(t) i_{s, q}(t)$

$\omega_{\Psi r o t}(t)=\frac{d \varphi_{\Psi r o t}(t)}{d t}=C_{2} \frac{1}{\Psi_{\text {rot }}(t)} i_{s, q}(t)$

Equation (4) states that if the RFOC method is used, that is, if the machine is forced to work with a constant $\Psi_{\text {rot }}$ magnitude, the instantaneous torque becomes proportional to $\mathrm{i}_{\mathrm{s}, \mathrm{q}}$ (which is the variable used to modify it, as just explained). But it follows from (5) that $i_{s, q}$ is proportional to the speed of $\Psi_{\text {rot }}$ with respect to the rotor, $\omega \Psi_{\text {rot }}$ (provided again, that the $\Psi_{\text {rot }}$ magnitude remains constant). Therefore, from an alternative perspective it can also be stated that in the RFOC the torque is proportional to the $\Psi_{\text {rot }}$ speed (more precisely: to the instantaneous $\Psi_{\text {rot }}$ slip) and that the quantity used to change the torque is just this speed (indirect RFOC). So, depending on the control variable considered, there are two equivalent ways to implement the strategy of keeping the $\Psi_{\text {rot }}$ amplitude constant: direct and indirect RFOC.

Notice that the second formulation does not resort to the concept of "field orientation" (a viewpoint very well explained in [4]), but rather points to the flux linkage space phasor speed. This perspective also provides a good physical insight into the transient process in that it allows us to easily correlate the fast build-up of torque with the way in which the currents must vary: to quickly increase the torque, the stator currents must suddenly change their phase angle in order to force a jump of the flux phasor speed. An increase in the magnitude of the currents, even if high and fast, will have little effect on a quick torque build-up if the mentioned phase angle variation does not take place. (This fact was already demonstrated and emphasized in a very clarifying manner in [22]).

Of course, the RFOC eliminates the pulsational emfs only 
in the rotor windings, whereas the ideal limit would be to eliminate them in all the machine windings. Therefore, it is only logical to ask how far away RFOC is from this limit. And the answer is that it is close to it.

To get this answer, one needs to analyze what happens to the $\Psi_{\text {str }}$ magnitude. To this end, we will make use of the two following equations:

$$
\begin{aligned}
& \overrightarrow{\Psi_{s t r}}=\overrightarrow{\Psi_{c o m}}+L_{\sigma, s t r} \overrightarrow{i_{s}} \\
& \overrightarrow{\Psi_{r o t}}=\overrightarrow{\Psi_{c o m}}+L_{\sigma, r o t} \overrightarrow{i_{r}}
\end{aligned}
$$

In these two equations, the second $\Psi$ component (leakage) is rather small in industrial motors, provided there are no big overcurrents. It can reach between 3 and $12 \%$ of $\Psi$. Therefore, for a first and fast estimate, it can be written:

$$
\left|\overrightarrow{\Psi_{\text {rot }}}\right|=\left|\overrightarrow{\Psi_{\text {com }}}+L_{\sigma, \text { rot }} \overrightarrow{i_{\text {rot }}}\right| \simeq\left|\overrightarrow{\Psi_{\text {com }}}\right| \simeq\left|\overrightarrow{\Psi_{\text {str }}}\right|
$$

that is, keeping the $\Psi_{\text {rot }}$ magnitude constant guarantees that $\Psi$ str magnitude variations will be small, and thus the stator pulsational emfs will be small as well.

Instead of keeping the $\Psi_{\text {rot }}$ magnitude constant, the other logical control option is to keep the $\Psi_{\text {str }}$ magnitude constant and achieve torque changes through variations of its speed.

As just explained, $\Psi_{\text {str }}$ and $\Psi_{\text {rot }}$ are rather similar space phasors (they would be the same in a motor with no leakage). But it has already been seen that if the $\Psi_{\text {rot }}$ magnitude is kept constant, the induction machine torque is exactly proportional to the $\Psi_{\text {rot }}$ slip. Therefore, if the $\Psi_{\text {str }}$ magnitude is kept constant, one can expect, for a first and fast estimate, that the torque will also be approximately proportional to the $\Psi_{\text {str }}$ speed with regard to the rotor (the " $\Psi_{\text {str }}$ slip"). This fact (quite easy to predict as to its qualitative results making use of the previous reasoning), was demonstrated in an already classical paper [7] in which the exact relationship between both variables is given and where it is explicitly written that "the quick torque response can be attained by using as much $\Psi_{\text {str }}$ - slip as possible". This idea, as explained in [7], constitutes the hard core of the DTC method, initially developed for induction machines.

The above explanations clearly show that from a conceptual point of view, RFOC and DTC in the induction machine are not so different as is usually stated. On the contrary, they can be better regarded as two logical options when trying to fulfil the GAFTOC requirements: RFOC maintains the $\Psi_{\text {rot }}$ magnitude constant while DTC does the same with $\Psi_{\text {est }}$, but both methods achieve very fast torque changes through steps in their 'slip-speed'.

Following this line of thought, we must be aware that, from a rigorous conceptual perspective, the DTC in [7] should actually be categorized as one of the possible variants to put the strategy of keeping the $\Psi_{\text {str }}$ magnitude constant into practice. Indeed, one can also perform the aforementioned strategy choosing as main control variable the stator current space phasor expressed in a reference frame tied to $\Psi_{\text {str }}$ and controlling the torque by means of $i_{\mathrm{sq}}$ (In this reference frame, unlike in the $\Psi_{\text {rot }}$ frame, $i_{\text {sd }}$ and $i_{\text {sq }}$ are coupled due to the influence of the machine transient reactance - [23], page 317 - and any change in $i_{\text {sq }}$ in order to meet a torque demand variation, will result in a stator flux change if $i_{\text {sd }}$ does not vary in a suitable manner). Therefore, a decoupling circuit is needed to adjust the $i_{\text {sd }}$ reference to changes in the $i_{\text {sq }}$ reference, so that the $\Psi_{\text {str }}$ magnitude remains constant during transients below the base speed). This is the SFOC method (Fig. 4).

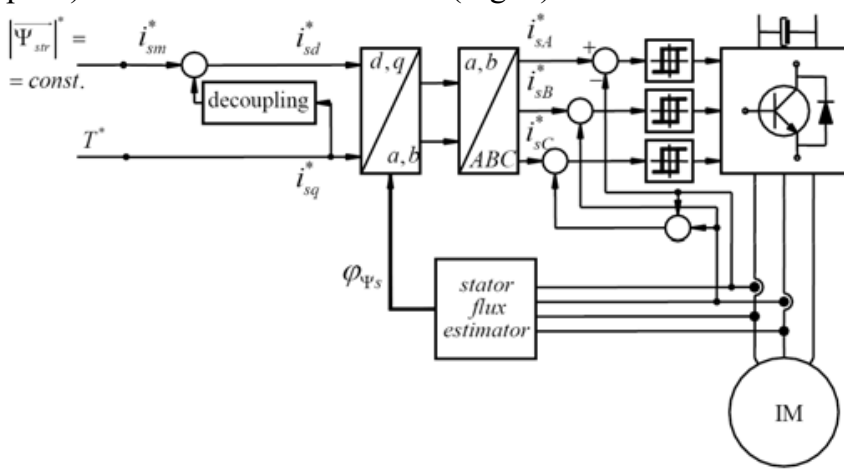

Fig.4. Stator Field Oriented Control of an induction machine

The initial resistances to accept the conceptual perspective on FOC and DTC established above are due to the fact that in the technical literature the essential nature and fundamental characteristic of the DTC method are almost always presented and understood from an operating perspective and they are primarily associated with the very simple and fast way the stator flux linkage phasor and the torque are controlled. The DTC method can also be very fast and easily deduced from Fig. 5 (a simple extension of Fig. 2 displayed to explain the FOC) again using the GAFTOC perspective as follows: since stator emf and stator voltage are almost equal quantities (negligible resistive voltage drop), the stator voltage phasor guides the stator flux phasor forcing it to approach a circular trajectory, so that only rotational emf emerges.

If $\overrightarrow{u_{s t r}} \cong-\overrightarrow{e_{s t r}}$, then according to (2):

$\overrightarrow{u_{s t r}} \cong \frac{d \overrightarrow{\Psi_{s t r}}}{d t} \Rightarrow \overrightarrow{\Delta \Psi_{s t r}} \cong \overrightarrow{u_{s t r}} \cdot \Delta t$

that is, during any converter control cycle the variation of the $\Psi_{\text {str }}$ phasor takes place very close to the direction of the voltage space phasor selected during the interval (Fig. 5).

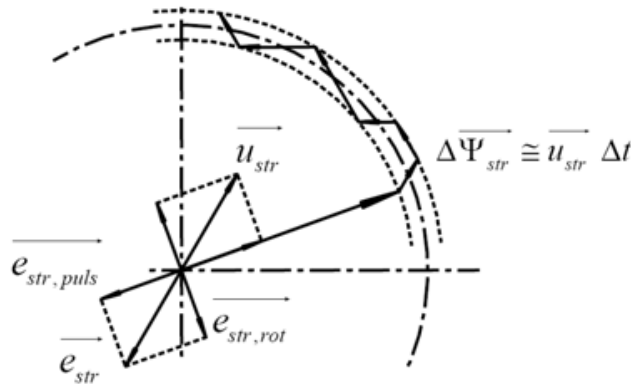

Fig.5. Stator flux phasor changes in a modulation step and stator pulsational and rotational emfs space phasors.

In other words, the amplitude of $\Psi_{\text {str }}$ is controlled by using radial voltage components (that is, pulsational emf, which only affects the flux magnitude), whereas the torque is adjusted by applying tangential voltage components (that is, rotational emf, directly related to the torque generation - as explained in 
Section II - and which only affects the speed of the flux phasor, producing a "tangential pull" on it). Thus, both the amplitude and speed of $\Psi_{\text {str }}$ can be controlled by selecting proper stator voltage phasors. Flux and torque errors are limited by hysteresis controllers. The switching state of the inverter, depending on the controllers' outputs and on the actual flux phasor position, is determined by a look-up table, which at the end of every control cycle selects the best voltage phasor from the different discrete values which the inverter can actually deliver (Fig. 6). In this way, whereas in other previous methods the inverter was modelled as an ideal controllable voltage or current source (which it is not) the DTC method takes into account the discontinuous nature and limits of the power source in the design process.

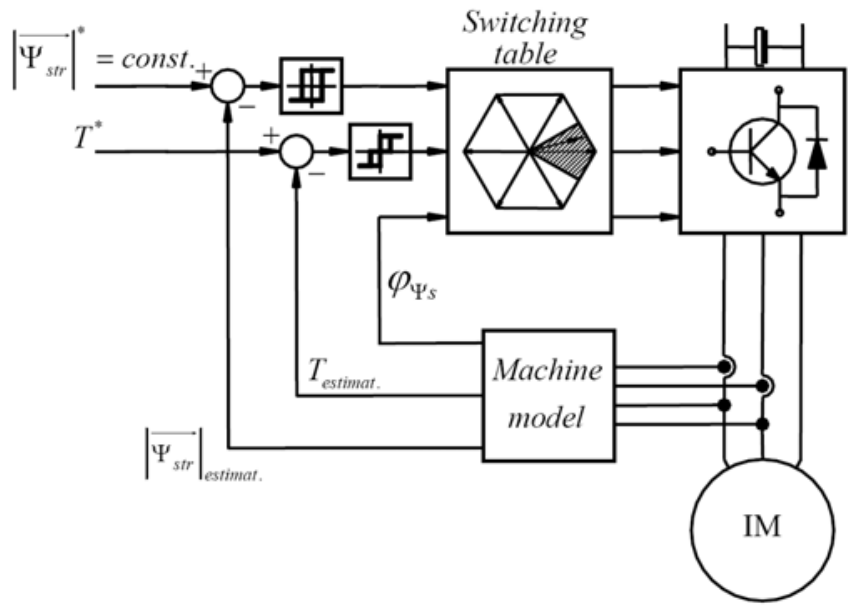

Fig.6. Direct Torque Control of an induction machine.

Due to this fact it is often stated that DTC must be dynamically better than any other method, because it always applies the maximum or the optimum voltage phasor (among all those which are actually available from the converter) to the motor, and this way it should develop the maximum response speed in guiding the motor variables to their reference values. But, theoretically, a similar behaviour also occurs with the FOC method, provided current hysteresis controllers are used: when a phase current leaves the hysteresis band around the reference value, it is forced to return to it always applying the maximum voltage the inverter is capable of to the phase input terminal. Of course, three phase hysteresis controllers (as those in Fig. 3 and Fig. 4) have some well known drawbacks [24] and PI controllers in $(\mathrm{d}, \mathrm{q})$ coordinates (see, for example [25]) are much more usual in commercial FOC schemes. However, the DTC in its primitive and quite attractive implementation also has its own disadvantages that have been addressed in different ways (see a survey in [19]), one of which is shown in Fig. 7. Notice again how clearly and easily the torque and stator flux control inputs in this figure are related to the two voltage components displayed in Fig. 5.

Contrary to the theoretical considerations in the preceding pages, there are practical aspects and technological criteria in which DTC and FOC do differ. These aspects, very important from an industrial viewpoint (parameter sensitivity, computation complexity, torque and current ripple in steady state, switching frequency, noise, losses, sensors required, etc) are mainly tied to the different particular ways in which the same general control philosophy can be implemented with today's technology. The comparison of DTC and FOC in relation to certain of these aspects has already been carried out, [26] and [27] and falls outside the scope of this paper.

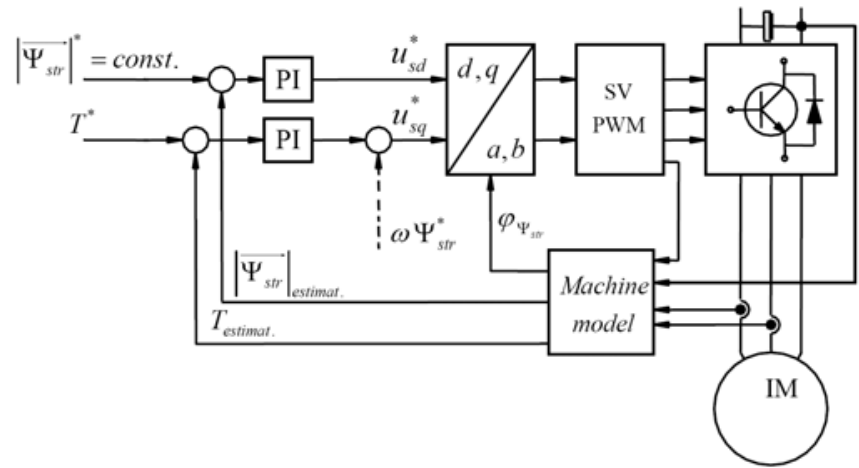

Fig.7. Direct Torque Control with constant modulation frequency of an induction machine. (Compensation term $\omega \Psi$ is optional)

\section{VERY FAST TORQUE CONTROL OF DOUBLY CONVERTER-FED ASYNCHRONOUS MACHINES (DFAM)}

Contrary to the induction motor, in the DFAM it is actually possible to keep the pulsational emfs null in all of its windings. To this end, the stator and rotor converters have to be operated to maintain $\Psi_{\text {str }}$ and $\Psi_{\text {rot }}$ magnitudes constant, as follows immediately from the GAFTOC. Actually, this idea of keeping $\Psi_{\text {str }}$ and $\Psi_{\text {rot }}$ magnitudes constant has been proposed very recently in [9] and [10] where it is presented as a further improvement over the latest and best proposal in the chain of previous developments over time concerning the DFAM [8]. In particular, the authors of [9] point out dynamic deficiencies as well as other drawbacks of the indirect airgap field oriented control in [8] and present their approach as superior. Notice that this is in line with the GAFTOC as an airgap field oriented control not aimed to keep both $\Psi_{\text {str }}$ and $\Psi_{\text {rot }}$ magnitudes constant does not eliminate all pulsational emfs.

In the case of DC (Section III), induction (Section IV) and PM synchronous machines (see next Section VI) there are hundreds of industrial drives and technical contributions which experimentally attest the very good dynamic performance of all control structures that this paper now derives as particular applications of the GAFTOC. The situation is different with regard to the DFAM and therefore this machine seems well suited to present some comparative results that highlight the GAFTOC possibilities, taking as starting point the control structure in [9].

Actually [9] is a very valuable and interesting contribution as it introduces for the first time a constant $\Psi_{\text {str }}$ and $\Psi_{\text {rot }}$ magnitude strategy for the DFAM torque control, but it still has place for improvement in two main aspects. On the one hand, the use of a classical V/f scalar law in the rotor side implies a loose and indirect rotor flux control (partial DTC, pDTC) that may result in rotor flux linkage oscillations especially during hard transients, and therefore in pulsational emfs being induced in the rotor windings. On the other hand, the rotor fre- 
quency profile chosen in pDTC unnecessarily forces the stator frequency to be close to its rated value throughout an extended speed range (about $\pm 1 / 2$ of rated speed around stall operation) disregarding the fact that torque control response is slowed down when the machine voltage gets close to the inverter ceiling voltage. In order to overcome both limitations the authors have proposed [20] the control structure in Fig. 8 (DTsrfC): the rotor $\mathrm{V} / \mathrm{F}$ controller of $\mathrm{pDTC}$ is substituted by an additional DTC type controller in the rotor side to keep the $\Psi_{\text {rot }}$ magnitude strictly constant (which constitutes the hard core of the GAFTOC) and this new DTC type controller also forces a field rotational speed (in the rotor fixed reference frame) set by a new rotor frequency profile that avoids operation of either stator or rotor converters close to their limits as much as possible.

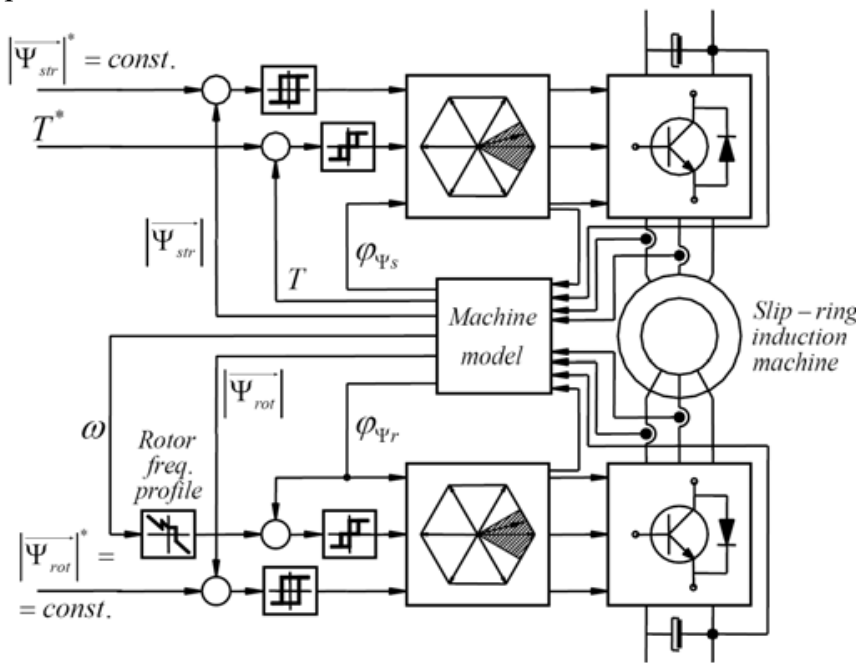

Fig.8. Direct Torque and Stator and Rotor Flux control of a DFAM. For more details, see [20]

Simulation results for a $11 \mathrm{~kW}$ machine in Fig. 9 show the improvement DTsrfC can provide over pDTC in torque response at twice rated speed. Fig. 10 explains the reasons for this improvement: while the DTsrfC keeps the rotor flux linkage magnitude strictly constant (but for the ripple) as required by the GAFTOC, the pDTC loose rotor flux control is prone to undesirable rotor flux magnitude (as well as d-axis currents) oscillations that degrade the torque response.

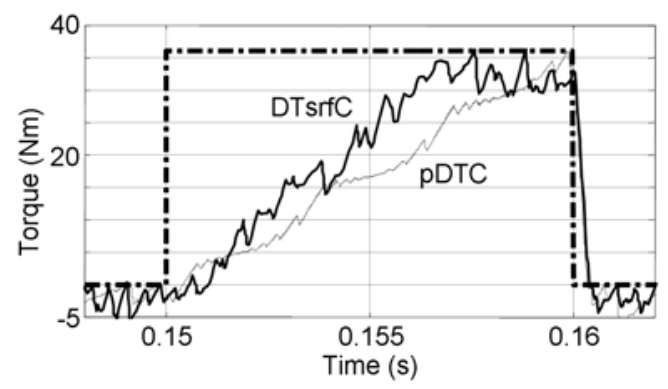

Fig.9. Response (DTsrfC and pDTC) to step changes in torque reference $(0 \sim$ $\mathrm{T}_{\text {rated }}$ ) at twice rated speed. Simulation on a $11 \mathrm{~kW}, 4$ pole motor. $\mathrm{R}_{\mathrm{s}}=0.32 \Omega$, $\mathrm{L}_{\sigma \mathrm{s}}=4 \mathrm{mH}, \mathrm{R}_{\mathrm{r}}=0.27 \Omega, \mathrm{L}_{\sigma \mathrm{r}}=5.3 \mathrm{mH}, \mathrm{L}_{\mu}=132 \mathrm{mH}$.

Similar simulation results have been observed in several machines in a wide power range, always confirming the two main reasons for the machine control improvement explained above (Notice that simulation reduces the masking influence of side effects, allowing in this case a fairer comparison of the torque dynamic performance which is the point under discussion). For more details on the DTsrfC see [20].
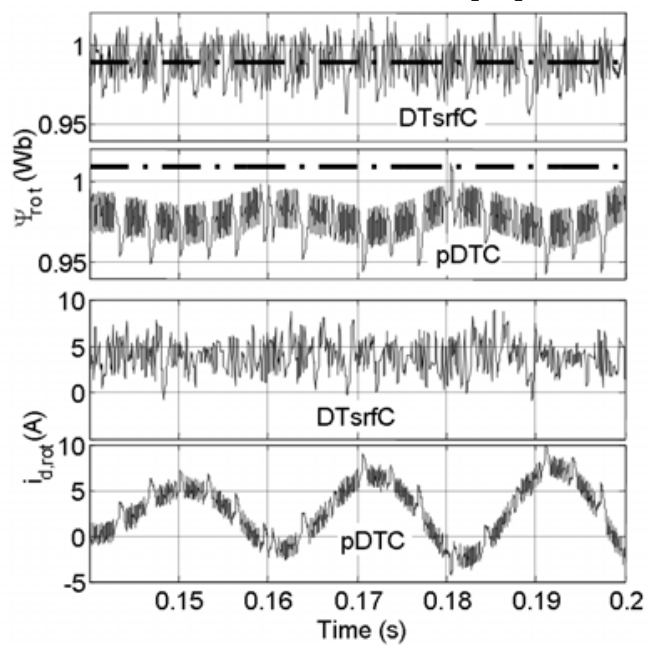

Fig.10. Rotor flux linkage (above) and d-axis current (below) for DTsrfC and pDTC during step changes in torque reference as in Fig. 9

\section{VERY FAST TORQUE CONTROL OF SYNCHRONOUS MACHINES WITH PERMANENT MAGNETS OR WITH WOUND ROTOR}

As has already been explained, the two conditions that must be met simultaneously for very fast torque control in an asynchronous machine (no pulsational emfs in its windings, just as in steady state) are:

$$
\left|\overrightarrow{\Psi_{s t r}}\right|=\text { Const. } \quad\left|\overrightarrow{\Psi_{\text {rot }}}\right|=\text { Const. }
$$

Let us refer in this section first to the synchronous motors with permanent magnet (PMSM).

In order to be able to apply to the whole machine the simple and powerful perspective of the circuit theory used for asynchronous machines, it is first necessary to replace the magnet by a suitable equivalent electric system (thus, avoiding being forced to resort to Maxwell's general field equations to account for the magnet). This is a simple task in the ideal PMSM: the magnet can be substituted by a single winding in the rotor fed from an ideal constant current source, since both systems work in the same way.

With this image in mind, it is clear that in order to avoid pulsational emfs emerging in the machine windings, the two requirements to be fulfilled (in a clear analogy with (8) and as already happens in the machine steady state) are:

$$
\left|\overrightarrow{\Psi_{s t r}}\right|=\text { Const. ; } \quad \Psi_{\text {rot }}(t)=\Psi_{\text {rot }}=\text { Const } \text {. }
$$

And again, since there is only one converter available in the stator, it becomes clear that it is impossible to meet both conditions simultaneously. And analogously to the case of the induction motor, there are also now two logical options: to keep constant either the magnitude of the stator flux linkage space phasor, $\Psi_{\text {str, }}$ or the value of the flux linkage corresponding to the single equivalent rotor winding.

The first option can be performed, among other possibilities, using the DTC procedure (see Fig. 11), as shown, for in- 
stance, in [13], [28]. As to the second option, since the rotor constant current does not self-induce any emf in its own winding, the solution is easy: the air gap magnetic field produced by the stator currents always has to be perpendicular to the magnetic axis of the rotor equivalent winding In this way, the magnitude variations in the stator field during transients will induce no emf at all in the equivalent rotor winding. This is the most widespread control method for these motors and has long been known (Fig. 12).

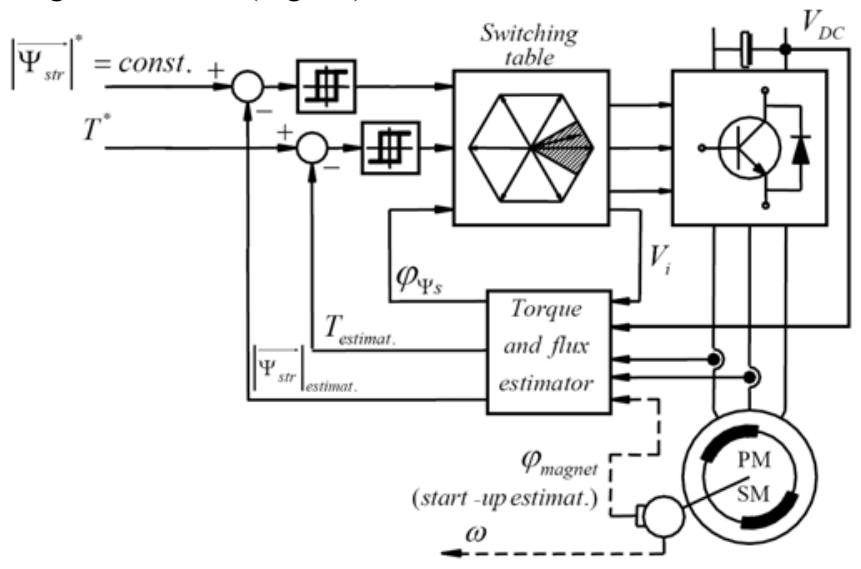

Fig.11. DTC control of a PMSM

Let us now consider the wound rotor synchronous machines. They have three windings (armature, field and damper winding), but only the first two can be connected to electronic converters. Therefore the dynamic pulsational emfs can be kept null simultaneously only in two windings and thus, there are various combinations to be tried and compared. To date, no study on this issue is available in the literature.

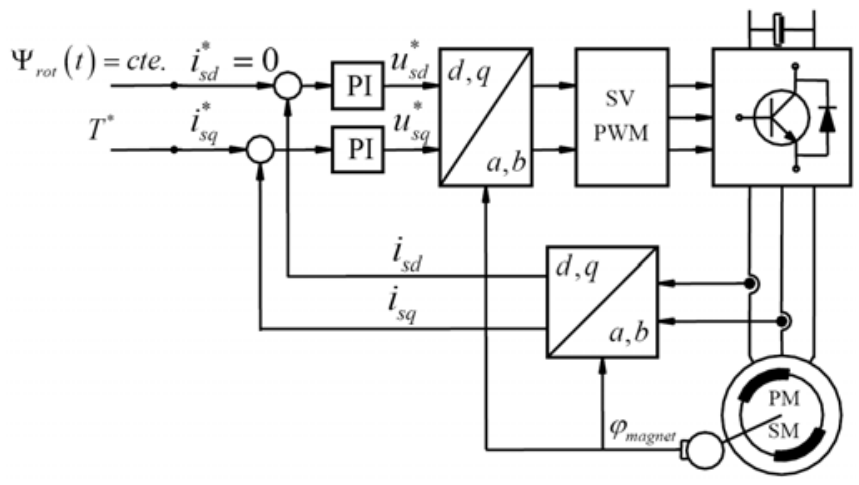

Fig.12. Rotor Field Oriented Control of a PMSM

Nevertheless, for a synchronous motor intended to be fed through a cycloconverter, the damper winding is often useless or even negative ([29] page 177 and [16]) and is usually not installed. Therefore, in such cases, according to (9), a good strategy will be to keep $\Psi_{\text {rot }}$ and the magnitude of $\Psi_{\text {str }}$ constant by means of the stator and rotor converters. If these two constant values are suitably selected, and if the load torque does not differ too much from the rated torque, this strategy also guarantees that in steady state the $\cos \varphi$ becomes practically equal to 1 . And it is precisely for large currents that it is of the utmost importance to achieve $\cos \varphi=1$, so that the con- verter need not be oversized.

A control variant used nowadays [16] is based on keeping

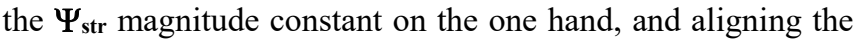
stator current and voltage space phasors, on the other hand. In this way, the stator current is always, that is, even in transient state and for any partial load, a purely "active" current (and thus $\cos \varphi=1$, which is very useful in high power drives). However, since the current variations in the field winding needed to keep the $\Psi_{\text {str }}$ magnitude constant in transients are not fast enough, due to the large field inductance, the method has some disadvantages as to high dynamic requirements. There are various ways of overcoming this drawback. Basically they rely on keeping the $\mathbf{i}_{\mathbf{s}}$ and $\mathbf{u}_{\mathbf{s}}$ space phasors aligned only in steady state, allowing the space phasor is to have a transient magnetizing component which is gradually reduced and eventually dies out as it is replaced by the action of the rotor current, the variations of which take much longer. A comparative study between this method and that derived from the GAFTOC will be given in a future paper.

\section{A NEW INSIGHT INTO THE SIMILARITIES AND DIFFERENCES BETWEEN FOC, DTC AND DSC}

According to the GAFTOC, torque changes are to be obtained exclusively enhancing the rotational emfs, which in turn implies that in polyphase windings the magnitude of the corresponding $\boldsymbol{\Psi}$ phasor must be kept constant. Notice that, although practically ignored, in fact this unifying principle underlies all of the fast AC control structures developed in the technical literature and reproduced in this paper, and thus, it is no wonder that, when analyzed from this perspective, a general similarity and a clear correspondence between all of these control schemes emerge.

In this sense, there is a general consensus that FOC and DTC are two clearly different methods, a statement which the authors do not agree with. In fact, from a conceptual viewpoint, FOC and DTC actually do pursue the same goal: to keep the $\Psi$ magnitude constant. What they do differ in is the way they use to achieve this goal. Regarding this issue, one could very briefly say that in the FOC the electrical variables primarily involved to access the $\Psi$ phasor and linked with it (and with the torque) are the currents, whereas in the DTC they are the voltages.

Take, for instance, the induction motor, where only the magnitude of either $\Psi_{\text {str }}$ or $\Psi_{\text {rot }}$ can be kept constant. Both possibilities can be realized through the FOC (SFOC and RFOC respectively) or through the DTC. In the DTC, the first variant corresponds to its classical mode of operation. To achieve the second, since $\Psi_{\text {str }}$ and $\Psi_{\text {rot }}$ are linked by the following equation $\left(\mathrm{C}_{1}\right.$ and $\mathrm{C}_{2}$ are two machine constants):

$\Psi_{\text {str }}=\sqrt{C_{1} \Psi_{\text {rot }}^{2}+C_{2}\left(T / \Psi_{\text {rot }}\right)^{2}}$

it suffices to modify the $\Psi_{\text {str }}$ reference value at the DTC input according to (10), in which $\Psi_{\text {rot }}$ is kept constant.

Electrical machines (in reality, "magnetic" machines) are based on the action of magnetic fields, that is, they are "cur- 
rent operated" devices ${ }^{3}$. Thus, the machine equations and their controls are easier to formulate in terms of currents. For this, FOC appears preferable. However, the controlled machine is fed through a converter which (except for current source inverters) works by impressing the voltage on the machine terminals. Therefore, from this perspective, using the voltages instead of the currents as the main electrical variables is much better.

FOC and DTC were initially developed for induction machines. Notice that the GAFTOC does not exclude the possibility of other methods with good dynamic response (based, e. g., on field energy considerations or on the so-called modern non linear control techniques). These methods of course will not eliminate the pulsational emfs completely neither in the stator nor in the rotor. However it is possible that, at least theoretically, some of them may keep the overall action of all of the machine pulsational emfs small or even smaller than FOC or DTC do. This is in contrast to the DFAM, in which the method described in Section $\mathrm{V}$ can not be surpassed for the elimination of these emfs

As to the DSC, the authors fully agree with the statement in [30], page 149: "DSC is often misrepresented as a subclass of DTC". Indeed, the driving idea behind the DSC in [5] and [6] (briefly: the on-off states of the inverter semiconductors can be directly controlled by comparing the time integrals of the line voltages to reference values, without any need for a frequency reference, hence the name self controlled) is clearly different from the way of thinking leading to the DTC in [7]. These differences become evident in the different $\Psi_{\text {str }}$ shape of both methods: hexagonal for the DSC and nearly circular for the DTC.

DSC does not meet the GAFTOC requirements. In the authors' opinion, the DSC is a very singular, extremely ingenious and highly valuable and effective control method. It is somewhat inferior to the DTC as regards dynamic response (presence of small pulsational emfs). However, for high power drives, where a reduced switching frequency together with small torque fluctuations are a must, DSC has undeniable advantages. Anyway, when switching frequency is not a concern, a circular $\Psi$ shape is clearly preferable.

\section{CONCLUSIONS}

Electromechanical energy conversion is directly concerned with the motional emf, while the pulsational emf provides a means of electrical energy transfer between magnetically coupled circuits. In fact, it is known that, in steady state of DC and symmetrical $\mathrm{AC}$ machines, the energy conversion process takes place under the exclusive presence of only rotational emfs (optimal utilization of resources).

The foregoing mode of operation must simply be applied to transient states too. In other words, achieving the torque variation by exclusively enhancing the rotational emfs also during transients must result in a control strategy with very fast dynamic torque response. This is the driving idea that runs

\footnotetext{
${ }^{3}$ The "true" electrical machines are really those based primarily on the electric, not the magnetic field and have been known for a very long time [31].
}

throughout the whole paper.

It should be added that the authors do not claim to have proven the previous statement in a mathematical way and presented it as the exact consequence of a theorem. Rather more, they have turned from merely mathematical to mainly physical considerations, and in this way (physical understanding first; equations only thereafter) they have brought into focus and drawn the attention to an extremely simple but undeniable fact with deep physical roots: electromechanical energy conversion is primarily concerned with motional emfs and thus pulsational emfs should be considered a waste of resources and time. Therefore, keeping these pulsational emfs as small as possible during transients (as already done in steady states) must always be a very good control option ranking among the best ones (if not just the best one).

The above general approach (GAFTOC), has been thoroughly checked and verified in this paper in that it has been particularized and applied to the DC machine, the squirrel cage motor, the doubly fed asynchronous machines and the synchronous machines with PM or with wound rotor. This has resulted in deducing in a unified, systematic and very easy way the control methods for these machines developed to date and regarded as the best from a dynamic point of view, and has shown that there is a general similarity and a clear correspondence between all of these control methods and schemes.

\section{APPENDIX}

According to Fig. 2 and to (2) in the main text, the fact that the rotor emf is purely rotational in the induction machine implies that the space phasors $\Psi_{\text {rot }}$ and e erot are perpendicular to each other, which in turn means that, according to (3), the irot and $\Psi_{\text {rot }}$ phasors are also orthogonal and therefore the locus of the air gap flux phasor $\overrightarrow{\Psi_{\text {com }}}=\overrightarrow{\Psi_{\text {rot }}}+L_{\sigma, r o t} \overrightarrow{i_{\text {rot }}}$

must be a straight line perpendicular to $\overrightarrow{\Psi_{\text {rot }}}$ (Fig. A.1).

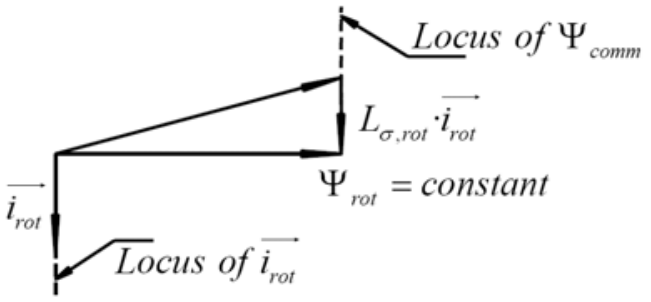

Fig. A.1

On the other hand, since it also holds for the phasor $\Psi_{\text {com }}$ $\overrightarrow{\Psi_{\text {com }}}=k\left(\overrightarrow{i_{\text {str }}}+\overrightarrow{i_{\text {rot }}}\right)$

and since the locus of $\Psi_{\text {com }}$ and of $\mathbf{i}_{\text {rot }}$ are perpendicular to $\Psi_{\text {rot, }}$ it follows that the locus of $\mathbf{i}_{\text {str }}$ must also be perpendicular to $\Psi_{\text {rot }}$ (Fig. A.2). In other words, keeping the $\Psi_{\text {rot }}$ magnitude constant in the induction motor (that is, inducing only rotational emfs in its rotor) implies shifting the affix of the istr phasor during any transient along a straight line perpendicular to $\Psi_{\text {rot }}$ as stated in Section IV. 


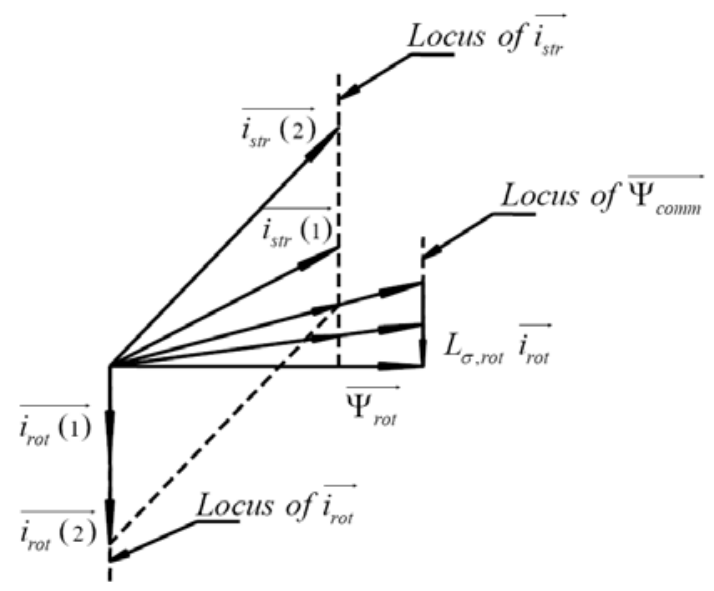

Fig. A.2

\section{REFERENCES}

[1] H. Ward Leonard, "Volts versus ohms. The speed regulation of electric motors" AIEE Transactions, Vol. 13, 1896, pp. 375 - 384

[2] K. Hasse, "Zur Dynamik drehzahlgeregelter Antriebe mit stromrichtergespeisten Asynchron-Kurzschlussläufermaschinen”. Ph.D. dissertation. Technische Hoschschule Darmstadt. 1969.

[3] F. Blaschke, "Das Prinzip der Feldorientierung, die Grundlage für die Transvektor-Regelung von Drehfeldmaschinen", Siemens Zeitschrift, Vol. 45, No 10, Oct. 1971, pp. 757-760

[4] F. Blaschke, "Das Verfahren der Feldorientierung zur Regelung der Drehfeldmaschine" Ph.D. dissertation. Tech. Univ. Braunschweig. 1974

[5] M. Depenbrock, "Direkte Selbstregelung für hochdynamische Drehfeldantriebe mit Stromrichterspeisung", ETZ Archiv, 7, No 7, July 1985, pp. 211- 218

[6] M. Depenbrock, "Direct self-control of inverte-fed induction machines", IEEE Trans. Power Electr., Vol. 3, No 4, Oct. 1998, pp. 420 - 429

[7] I. Takahashi and T. Noguchi: "A new quick-reponse and highefficiency control strategy of an induction motor", IEEE Trans. Ind. Applicat. Vol 1A-22, No 5, Sept./Oct. 1986, pp. $820-827$

[8] Y. Kawabata, E. Ejigou and T. Kawabata,"Vector-controlled doubleinverter-fed wound rotor induction motor suitable for high powe drives", IEEE Trans. Ind. Applic. Vol.35, pp. 1058-1066, Sept-Oct 1999

[9] G. Poddar, V.T. Ranganathan, "Direct torque and frequency control of double-inverter-fed slip-ring induction motor drive", IEEE Trans. Ind. Electronics, Vol. 51, pp. 1329-1337, Dec. 2004

[10] G. Poddar, V.T. Ranganathan, "Sensorless double- inverter-fed woundrotor induction-Machine drive" IEEE Trans. Ind. Electronics, Vol. 53, Feb. 2006, pp. 86-95

[11] W. Leonhard, "Control of Electrical Drives", Springer Verlag, Berlin Heidelberg, 1996

[12] A. Consoli, S. Musmeci, A. Raciti, A. Testa, "Sensorless vector and speed control of brushless motor drives", IEEE Trans. Ind. Electronics, vol. 41, no 1, Feb 1994, pp 91-96

[13] L. Zhong M. F. Rahman, W.Y. Hu, K.W. Lim and M.A. Rahman, "A direct torque controller for permanent magnet synchronous motor drives", IEEE Trans. En. Conv. Vol 14, No 3, Sept. 1999, pp. 637 - 642

[14] K. H. Bayer, H. Waldmann and M. Weibelzahl. Field-oriented closedloop control of a synchronous machine with the new transvektor control system. Siemens Rev. vol. 39, No 5, May 1972, pp. 220-223

[15] M. Meyer, "Elektrische Antriebstechnik", Vol I and II., Springer Verlag, Berlin - New York, 1987. See pages 119-122 in Vol. II

[16] H. Stemmler, "High-Power industrial drives". Proceedings of the IEEE, Vol. 82, No 8, August 1994, pp. 1266 - 1286

[17] J. Pyrhönen, O. Pyrhönen, M. Niemelä, J. Luukko, J. Kaukonen "Direct torque control of synchronous motor drives for dynamically demanding applications", ETEP, Vol. 10, No 5, Sept /Oct. 2000, pp. 297 - 304

[18] B. K. Bose "Modern Power Electronics and AC Drives" Prentice Hal PTR, NJ, 2002

[19] G.S.Buja and M.P.Kazmierkowski, "Direct torque control of PWM inverter-fed AC motors: a survey". IEEE Trans. Ind. Electronics, Vol. 51, No 4, August 2004, pp. 744 - 757
[20] J. Martínez-Román, L. Serrano-Iribarnegaray, "Direct Torque and Stator and Rotor Flux Control of Doubly Converter Fed Induction Machines" IEEE MELECON 2006, pp. 1158-1161

[21] L. Serrano-Iribarnegaray, "The Space Phasor Theory" in H. Bülent, M. Yildirin, R. Colyer and A. Consoli (Editors) "Modern Electrical Drives" Kluwer Academic Publisher, Doordrecht / Boston, 2000, pp. 393 - 423

[22] M.P. Kazmierkowski and H.J. Köpcke, "Vergleich dynamischer Eigenschaften verschiedener Steuer- und Regelverfahren für umrichtergespeiste Asynchronm.”, ETZ Archiv, 4, No 9, 1982, pp. 269 - 277

[23] Bühler, H.: Einführung in die Theorie geregelter Drehstromantriebe, Vol I and II. Birkhaüser, Stuttgart, 1977.

[24] M.P. Kazmierkowski and M. Malesani, "Current control techniques for three-phase voltage-source PWM converters: a survey", IEEE Trans. Ind. Electronics, Vol. 45, No 5, Oct. 1998, pp. 691 - 703

[25] K. Ohishi, E. Hayasaka, T. Nagano, M. Harakawa, and T. Kanmachi, "High-Performance Speed Servo System Considering Voltage Saturation of a Vector-Controlled Induction Motor", IEEE Trans. Ind. Electronics, Vol. 53, No 3, June 2006, pp. 795 - 802

[26] Hoang Le-Huy, "Comparison of field-oriented control and direct torque control for induction motor drives" Industry Applications Conference, 34 IAS Annual Meeting, Vol. 2, 3-7 Oct. 1999, pp. 1245 - 1252

[27] D. Casadei, F. Profumo, G. Serra and A. Tani, "FOC and DTC: Two viable schemes for induction motors torque control", IEEE Trans. Power Electronics, Vol. 17, No 5, Sept. 2002, pp $779-787$

[28] M. Pacas and J. Weber, "Predictive Direct Torque Control for the PM Synchronous Machine", IEEE Trans. Ind. Electronics, Vol. 52, No 5, Oct. 2005 , pp. 1350 - 1356

[29] H. Kleinrath, "Stromrichtergespeiste Drehfeldmaschinen" Springer Verlag. Wien, 1980

[30] A. M. Trzynadlowski, "Control of induction motors" Academic Press, San Diego (CA) 2001.

[31] L. Serrano-Iribarnegaray, "The Space-Phasor Theory” ICEM'96 Proceedings, Plenary Session 2, Vol. II, pp. 1-13, Sept. 1996

[32] F. Ollendorf, "Ueber Kapazitätsmaschinen" Archiv für Elektrotechnik", Vol. 12, July 1923, pp. 297-319

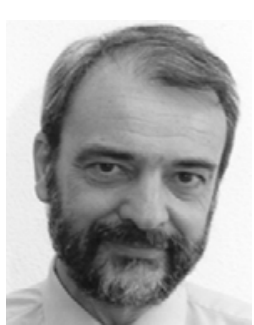

L. Serrano-Iribarnegaray (1949) received his Dipl. Ing. and Dr. Ing. degrees in electrical engineering from the Universities of Bilbao and Madrid (Spain) in 1971 and 1978, respectively. From 1972 to 1976 he worked in the field of thyristor-controlled d.c. machines in the AEG-company in Spain and Germany and spent thereafter 15 months investigating at the Institut für Regelungstechnik of the Technische Universität Braunschweig/Germany. Since 1982 he has been holding the chair for theory and control of electrical machines at the Universidad Politécnica de Valencia/Spain. He has written two books in Spanish, has published more than 10 papers on electrical machines in international journals and has been the scientist responsible in Spain for various international projects supported by the European Union.

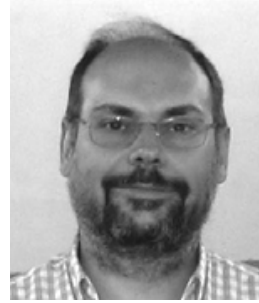

J. Martínez-Román (Alicante, Spain 1965) received his Dipl. Ing. and Dr. Ing. degrees in electrical engineering from the University of Valencia (Spain) in 1991 and 2002, respectively. He joined the Universidad Politécnica de Valencia in 1994 first as researcher (training) and then in 1997 as fulltime Assistant Professor in the Department of Electrical Engineering, in the area of theory and control of electrical machines. He has participated in various international projects supported by the European Union. He has published several papers on electrical machines in international journals and conferences. His interests include electrical machines and drives. 